\title{
Improving outcomes in older people undergoing elective surgery
}

\author{
J Dhesi \\ Consultant Geriatrician, Department of Ageing and Health, Guy's \& St Thomas' Foundation Hospital Trust, London, UK
}

This review is based on a presentation given by Dr Dhesi at the RCPE Care of the Elderly Symposium on 15 September 2010.

\begin{abstract}
Older people have much to gain from surgery, but pose a significant challenge not only in emergency surgery but also in elective surgery. Despite significant progress in the care of older surgical patients, they remain more likely to 'fail' pre-assessment and have higher rates of post-operative complications than younger people. The evidence suggests that this is a consequence of agerelated increases in co-morbidities and reduction in physiological reserve. Numerous studies have demonstrated improvements in outcome when individual co-morbidities are appropriately assessed and optimised. However, current models of care do not allow for the translation of this evidence into routine clinical practice, particularly in those with complex co-morbidities and functional dependence. This article explores the reasons for poor outcome in older people and describes an alternative model of care for the older elective surgical patient.
\end{abstract}

KEYWORDS Comprehensive geriatric assessment, elderly, elective surgery, older people, pre-operative

DECLARATION OF INTERESTS No conflict of interests declared.
Correspondence to J Dhesi, Department of Ageing and Health, Guy's \& St Thomas' Foundation Hospital Trust, Westminster Bridge Road, London SEI 7EH, UK

tel. +44 (0)20 71882092 e-mail jugdeep.dhesi@gstt.nhs.uk

\section{INTRODUCTION}

With the changes in demographics and in surgical and anaesthetic techniques, more and more older people are undergoing elective surgery. This is apparent across surgical subspecialties. ${ }^{1-3}$ The benefits of surgery in the elderly are comparable to the younger population, namely improvements in symptom and pain control, functional status and quality of life. ${ }^{4}$ Indeed, in hip and knee arthroplasty in persons aged more than 80 years, the most dramatic post-operative functional gains have been demonstrated in the most disabled of patients. ${ }^{5}$ In older patients with cancer, although curative surgery occurs less commonly, the results in terms of 30-day mortality are similar to younger people..$^{6-8}$

Despite the benefits seen with surgery in older people, they are more likely to be considered to have a clinical profile that is 'too risky for surgery', which potentially reduces their access to effective elective procedures. Those who have surgery do indeed have a high rate of complication, with one fifth of patients aged 70 or more undergoing non-cardiac surgery developing one or more serious post-operative complication. ${ }^{8-12}$ Although the rate of surgical complications in older patients is comparable with that of younger patients, the rate of medical complications is much higher. For example, in a systematic review of colorectal surgery, older people had significantly more post-operative medical complications, while there was no significant difference in anastomotic leaks. ${ }^{8}$ Furthermore, older people often tolerate these complications less well than younger patients as a consequence of a reduction in physiological reserve seen with ageing and/or co-morbidity. Worryingly, the occurrence of post-operative complication has been shown to be more important than pre-operative patient risk and intra-operative factors in determining survival after major surgery. ${ }^{13}$ Not surprisingly, older people have a longer length of stay than younger people, predominantly as a result of the post-operative complications, but also as a result of difficulties in discharge from hospital. ${ }^{7,10,14,15}$

This article explores the reasons why older people have a higher chance of adverse post-operative outcome and describes methods whereby outcomes may be improved.

\section{PREDICTORS OF ADVERSE POST-OPERATIVE OUTCOME}

Several multivariate studies have shown that the primary pre-operative risk factor for poor post-operative outcome is not age but co-morbidity., ${ }^{9,17}$ Cardiac disease, in particular ischaemic heart disease, heart failure and arrhythmia, and reduced physiological reserve are the strongest predictors of post-operative problems. . $^{96-18,19}$ Pulmonary disease, dementia, poor nutrition and, more recently, anaemia have also been implicated. .7,20,21 $^{2}$ Interestingly, age is an independent predictor of surgical site infections and respiratory failure but not of cardiac events or venous thromboembolism. ${ }^{22,23}$ 
Cardiac disease is prevalent in the older population, but in many it may be asymptomatic and/or unrecognised; silent ischaemia is common in the elderly and in diabetics or may be masked by poor exercise tolerance. Postoperative cardiac complications are common and particularly serious in the elderly with a higher mortality in the older compared with the younger population..$^{24,25}$

The other factor consistently identified as an independent risk factor for adverse outcome is 'functional reserve' or cardiorespiratory/physiological reserve. ${ }^{19}$ Normal ageing affects the resting function of many organs such that the fit older person has a lower functional reserve and ability to 'deal' with physiological stress. However, when pathology is superimposed on physiological change, then there is a further reduction in reserve capacity. It is that reserve capacity that is called upon during times of stress such as surgery, with increases in metabolic requirements, often in the setting of a catabolic state (i.e. cancer or inflammatory processes). In the past surgeons have relied on the 'end of the bed test' (a visual inspection) to assess functional reserve. More recently, objective measures such as cardiopulmonary exercise testing (CPET) $)^{19,26}$ and metabolic equivalents (METs) ${ }^{27}$ have gained popularity. In a similar vein, frailty, which may be defined by clinical judgement, frailty scales or by operational means, is an independent and additional risk factor for poor outcome. ${ }^{28,29}$

As it is estimated that $50 \%$ of those aged over 75 years have a limiting chronic condition, most often cardiorespiratory, metabolic or neurological, ${ }^{30}$ and as $10-15 \%$ of those aged over 80 years are deemed frail, ${ }^{31}$ it is not surprising that this group has the poorest postoperative outcome.

Taking this evidence into account, it would seem that post-operative outcomes in older people could be improved by ensuring that patients are optimised for surgery. This requires the clinical application of the evidence base throughout the elective surgical pathway, targeting those most at risk. In the following sections these issues are discussed in more detail.

\section{IMPROVING OUTCOMES BY APPLYING THE EVIDENCE BASE FOR MEDICAL MANAGEMENT OF THE SURGICAL PATIENT}

There is a growing evidence base for the assessment and peri-operative management of organ-specific disease. In some specialties this has been summarised into extremely useful clinical guidelines, such as those from the American College of Cardiology or the European Society of Cardiology on peri-operative cardiovascular evaluation for non-cardiac surgery. ${ }^{32,33}$ These guidelines summarise risk assessment, the need for pre-operative investigation and the evidence base for the use of beta blockers and statins in user-friendly algorithms. Similarly, the American College of Physicians has published a guideline on the risk assessment and management of peri-operative respiratory complications based on systematic reviews. ${ }^{34}$ These existing guidelines are very welcome but require considered application in the context of the older population. This is because of the prevalence in this population of multiple co-morbidities, polypharmacy, issues with compliance and the practical and costrelated problems of attending multiple appointments for investigation and review.

Guidelines are less clear, less available and not as easily applicable in the case of co-morbidities other than cardiorespiratory disease. For example, it is known that anaemia on admission results in a higher incidence of infection, increased risk of peri-operative myocardial ischaemia and increased 30-day mortality. ${ }^{20,35,36}$ There is growing evidence that pre-operative interventions such as a correction of iron deficiency can reduce the need for post-operative transfusion. ${ }^{20,37}$ However, this evidence base is not well known to the pre-assessment nurses who routinely see these patients and is therefore not often taken into account. In other situations the importance of the context of the problem is not always understood. For example, the implication of low-grade anaemia, e.g. in a frail elderly patient with subclinical ischaemic heart disease, may not be appreciated by junior surgical staff.

Further difficulties arise in developing and applying guidelines for the more 'multidisciplinary' areas, such as nutrition. Despite the importance of malnutrition as a predictor of adverse outcome ${ }^{17,18,23}$ and the widespread availability of nutritional assessment tools, it is often recognised late. Furthermore, as the evidence for timing, duration and type of intervention is uncertain, a standardised approach is not applied.

Other issues require close multidisciplinary working, for example delirium. There is a good evidence base to allow the pre-operative identification of patients who are at high risk of post-operative delirium. ${ }^{38-40}$ However, this risk is rarely communicated to anaesthetic staff, who could ensure vigilant intra-operative monitoring and management (for example, of peri-operative blood pressure lability); to surgical ward staff, who could ensure that evidence-based strategies to reduce the severity, duration and impact of delirium are implemented; ${ }^{41-43}$ or to old-age psychiatrists, who could assist in the pharmacological management if required. Once delirium is established it is often not recognised and its impact on the patient, in-hospital mortality and rates of institutionalisation are not appreciated by surgical staff. ${ }^{41-46}$ Evidence suggests that 'hands on' geriatric input is needed to implement delirium strategies and to change clinical practice..$^{43,47}$

In summary, while there is an evidence base for improving medical management of the surgical patient, it is not easily applicable to a patient with multiple co-morbidities nor is 
it easily accessible to those who provide direct care for older surgical patients.

\section{IMPROVING OUTCOMES BY CHANGING THE ELECTIVE CARE PATHWAY}

As discussed, some of the major risk factors for adverse post-operative outcome, namely co-morbidity and functional reserve, are potentially modifiable. This implies that careful pre-operative assessment and management may be the key to preventing post-operative complications. To achieve this, the pre-assessment process needs to focus on the recognition of known co-morbidity, the identification of unrecognised disease and the assessment of functional reserve. However, it also needs to be taken as an opportunity to optimise the medical, functional, psychological and social condition of the patient, in order to get the patient as 'fit as possible' for surgery.

The pre-assessment process can also allow the prediction of likely post-operative complications, so that surgical and anaesthetic teams can be prompted to identify medical complications early and thereby allow a more planned and standardised approach to the management of these complications. This will facilitate multidisciplinary working between surgical, anaesthetic, intensive care and elderly care teams. The involvement of a geriatrician may aid a multidisciplinary approach to capacity, consent and advanced directives. It also allows early discharge planning with the identification of those who are most likely to require additional support and/or rehabilitation in the post-operative phase.

Unfortunately, the prevalent models of care are narrowly focused on the surgical issue with which the patient presents. The majority of pre-assessment clinics are nurse-led, often nurses with extensive surgical backgrounds but very little elderly care experience. The nurse uses a proforma and either identifies the patient as being 'fit for surgery' or as requiring further assessment. If further review is required, the referral is returned to the general practitioner (for example, for hypertension control) or to an anaesthetist or medical specialist such as cardiologist for specialist medical input. Unfortunately, this results in a significant proportion of patients being, at best, delayed for surgery and, at worst, not receiving the necessary surgery.

Surveys and case note reviews suggest that pre-operative referrals for medical assessment to organ specialist physicians result in little advice that truly impacts either on peri-operative management or the outcome of surgery. ${ }^{48}$ In one study, $40 \%$ of cardiac consultations made no recommendation other than 'proceed with surgery' or 'cleared for surgery'. ${ }^{49}$ This suggests that either the referrals were inappropriate or that the reviewing physician was focused on the single organ pathology.
Anaesthetists do review patients in pre-assessment clinics, but often this is for the patient with complex anaestheticrelated issues. They more often see patients on the day of surgery with limited medical information. This reduces the opportunity to make minor intra-operative adjustments which may have significant clinical implications (for example, tight control of blood pressure in a patient with mild cognitive impairment may reduce delirium).

Furthermore, post-operative care on the surgical ward is most often provided by junior surgical doctors, with advice from on-call medical teams, despite this being a high-risk population. The on-call model leads to fragmented medical care in the critical post-operative period. Geriatrician opinions are occasionally sought, but in a reactive manner rather than pre-empting issues proactively, and often late in the admission.

An alternative model is the 'POPS' model (Proactive care of Older People undergoing Surgery) illustrated in Figure I. The hypothesis underlying this model is that pre-operative comprehensive geriatric assessment (CGA), which incorporates the prediction of adverse outcomes, combined with targeted interventions (preand post-operatively), reduces post-operative complications and hence the length of stay in older people. This model was established at Guy's and St Thomas' Hospital, London, in 2005, with initial funding from the Guy's and St Thomas' Charity.

The POPS model ensures that the older patient with medical co-morbidities or functional dependence is followed throughout the surgical journey by a multidisciplinary elderly care team. Pre-operatively, the team uses CGA methodology to assess and optimise the patient for surgery, to predict unavoidable post-operative complications, to predict post-operative rehabilitation or care needs and to communicate these issues with involved healthcare professionals and families/carers. This allows a proactive rather than a reactive approach. The team then follows the patient through to admission and provides regular medical input, helping the surgical team in the early identification and standardised management of medical complications. POPS has established ward-based multidisciplinary team meetings with an emphasis on early, safe and effective discharge planning.

Data published from a pre- and post-POPS study conducted in orthopaedic elective patients demonstrated reductions in post-operative medical complications (delirium, pneumonia, pressure sores), improvements in pain control and mobilisation and reductions in length of stay. ${ }^{47}$ As a consequence the POPS service received mainstream trust funding. Since then the service has become embedded into the routine care of older people undergoing elective surgery (as well as expanding to cover emergency surgery) across all the major surgical specialties based at this large London teaching hospital. 


\section{Targeting the patient}

Referral criteria based on co-morbidities and

functional impairment known to affect post-

operative outcome

Sources:

- Surgical referral from outpatient department

- GP referral

- Waiting list screening

- Deferred cases

\section{Community}

Use of local intermediate-care services

Follow-up

- Medical

- Physiotherapy/occupational therapy

- Health promotion

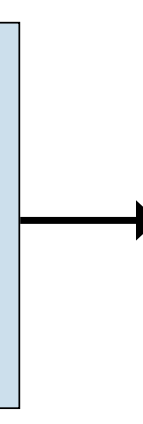

Pre-operative assessment

Multidisciplinary assessment leading to targeted intervention

Medical and nursing

- Comprehensive geriatric assessment

- Medical/nursing risk stratification and optimisation

Physiotherapy

- Cardiovascular and respiratory assessment and intervention

- Falls assessment, muscle strengthening and balance training

- Pelvic floor training

Occupational therapy

- Optimisation of home circumstances

- Timely provision of equipment

Social worker

- Provision of services/benefits pre-operatively

- Assessment of potential discharge concerns

Hospitalisation

Surgical ward rounds by geriatrician and

specialist nurse

- Early and standardised management of postoperative complications

Ward-based multidisciplinary meetings

- Facilitate therapy liaison

- Implement timely discharge planning

Education for surgical nursing and medical staff

- Medical issues

- Geriatric giants (immobility, instability, incontinence and impaired intellect)

- Discharge planning

FIGURE I A model for proactive care of older people undergoing surgery used at Guy's and St Thomas' Hospital, London. ${ }^{47}$

Staff and patient questionnaires have demonstrated a high level of satisfaction with the service.

Furthermore, over the past five years, post-operative outcomes have steadily improved, reflected by routinely collected data demonstrating that the older, frailer cohort attending for elective surgery now has a similar length of stay as a young, fit cohort. This has occurred as a consequence of pre-operative optimisation resulting in fewer medical complications, which are recognised earlier and managed by advice from a single team in a proactive manner. In addition, the team ensures appropriate discharge planning and for this a knowledge base of the local rehabilitation services and the provision of social services has been invaluable.

\section{THE EVIDENCE GAP}

The evidence base for improving outcomes in older people having surgery is growing. However, many questions with regards to the clinical management of this population remain unanswered. There are questions related to the geriatric syndromes, for example, whether nutritional or physiotherapy interventions for frailty can reduce its impact as an independent predictor for adverse post-operative outcome. Then there are questions regarding medical conditions. One example is anaemia: Should iron stores be checked in all older surgical patients and does supplementation improve clinical outcome? In addition, there are questions that can be answered only by complex interventions: Can post-operative delirium be reduced by pre-operative optimisation in conjunction with intra-operative interventions? There are questions relating to the process and cost effectiveness of care such as: Who should be implementing guidelines? Should it be the preassessment services, primary care services or organ specialists or should a new specialty of 'peri-operative medicine for the elderly' be considered? And, finally, how should one organise the education and training of the workforce in order to meet the needs of this growing population? 


\section{THE FUTURE}

Older patients are a high-risk surgical population by virtue of their associated co-morbidities and reduction in functional reserve. However, it needs to be recognised that increasing numbers of older people will require elective surgery. In order to provide a high-quality and cost-effective service, different models of care need to be considered for this population. Methods need to be developed for translating the existing evidence base for single organ disease assessment and management into routine clinical practice for older people with multiple co-morbidities. It is time to move on from developing risk assessment tools to developing interventions to reduce post-operative complications and mortality. In order to do this, the development of integrated care pathways needs to be considered, using the skills of surgical teams, anaesthetic teams, organ specialists and geriatricians. There is a need for a medical specialty to take the lead in providing continuity of medical care for older people having elective surgery. One could argue that geriatrics is best placed to take this forward.

\section{REFERENCES}

I Klopfenstein CE, Herrmann FR, Michel JP et al. The influence of an aging surgical population on the anesthesia workload: a ten-year survey. Anesth Analg 1998; 86:II65-70. doi:10.1097/00000539. 199806000-00005

2 Pofahl WE, Pories WJ. Current status and future directions of geriatric general surgery. J Am Geriatr Soc 2003; 5I:S35I-4. doi:I0.1046/j.I365-2389.2003.5I347.x

3 Birrell F, Johnell O, Silman A. Projecting the need for hip replacement over the next three decades: influence of changing demography and threshold for surgery. Ann Rheum Dis 1999; 58:569-72. doi: I0.1 I36/ard.58.9.569

4 Ethgen O, Bruyere O, Richy F et al. Health-related quality of life in total hip and knee arthroplasty: a qualitative and systematic review of the literature. J Bone Joint Surg Am 2004; 86:963-74.

5 Brander VA, Malhotra S, Jet J et al. Outcome of hip and knee arthroplasty in persons aged 80 years and older. Clin Orthop Relat Res 1997; 345:67-78. doi: I0.1097/00003086-1997/2000-000 I I

6 Tan E, Tilney H, Thompson $M$ et al. The United Kingdom National Bowel Cancer Project: epidemiology and surgical risk in the elderly. Eur J Cancer 2007; 43:2285-94. doi:10.1016/j. ejca.2007.06.009

7 Hamel MB, Henderson WG, Khuri SF et al. Surgical outcomes for patients aged 80 and older: morbidity and mortality from major noncardiac surgery. J Am Geriatr Soc 2005; 53:424-429. doi: I 0.I I II/ j. I532-54I5.2005.53I59.x

8 Colorectal Cancer Collaborative Group. Surgery for colorectal cancer in elderly patients: a systematic review. Lancet 2000; 356:968-74. doi:I0.1016/S0I40-6736(00)027/3-6

9 Liu LL, Leung JM. Predicting adverse postoperative outcomes in patients aged 80 years or older. J Am Geriatr Soc 2000; 48:405-12.

I0 Polanczyk CA, Marcantonio E, Goldman L et al. Impact of age on perioperative complications and length of stay in patients undergoing noncardiac surgery. Ann Intern Med 200 I; I34:637-43.

II Mantilla CB, Horlocker TT, Schroeder DR et al. Frequency of myocardial infarction, pumonary embolism, deep venous thrombosis, and death following primary hip or knee arthroplasty. Anesthesiology 2002;96: I |40-6.doi: 10.1097/00000542-20020500000017

I2 Roche JJ, Wenn RT, Sahota O et al. Effect of comorbidities and postoperative complications on mortality after hip fracture in elderly people: prospective observational cohort study. BMJ 2005; 33I:I374-6. doi:I0.I I36/bmj.38643.663843.55

13 Khuri SF, Henderson WG, DePalma RG et al. Determinants of long-term survival after major surgery and the adverse effect of postoperative complications. Ann Surg 2005; 242:326-43.

14 O'Toole GC, Abuzukuk T, Murray P et al. Elective total hip arthroplasty in patients aged 85 years and older. Ir Med PPJ 2002; 95:106-7.

I5 Marcantonio ER, Goldman L, Orav EJ et al. The association of intraoperative factors with the development of postoperative delirium. Am J Med 1998; 105:380-4. doi:10.1016/S00029343(98)00292-7
I6 Turrentine FE, Wang $\mathrm{H}$, Simpson VB et al. Surgical risk factors, morbidity and mortality in elderly patients. J Am Coll Surg 2006; 203:865-77. doi:I0.1016/j.jamcollsurg.2006.08.026

17 Leung JM, Dzankic S. Relative importance of preoperative health status versus intraoperative factors in predicting postoperative adverse outcomes in geriatric surgical patients. J Am Geriatr Soc 200I; 49:I080-5. doi:I0.I046/j.I532-54I5.200I.492I2.x

I8 Neumayer L, Hosokawa P, Itani K et al. Multivariable predictors of postoperative surgical site infection after general and vascular surgery: results from the Patient Safety in Surgery Study. J Am Coll Surg 2007; 204:I I78-87. doi:I0.1016/j.jamcollsurg.2007.03.022

19 Older P, Hall A, Hader R. Cardiopulmonary exercise testing as a screening test for perioperative management of major surgery in the elderly. Chest 1999; I 16:355-62. doi: 10.1378/chest. I 16.2.355

20 Myers E, Grady PO, Dolan AM. The influence of preclinical anaemia on outcome following total hip replacement. Arch Orthopaed Trauma Surg 2004; 124:699-701. doi: 10.1007/s00402-004-0754-6

21 Mangano DT. Perioperative cardiac morbidity. Anesthesiology 1990; 72: 153-84. doi:10.1097/00000542-199001000-00025

22 Rogers SO Jr, Kilaru RK, Hosokawa $\mathrm{P}$ et al. Multivariable predictors of postoperative venous thromboembolic events after general and vascularsurgery: results from the Patient Safety in Surgery Study. J Am Coll Surg 2007; 204:I2II-2I. doi:10.1016/j.jamcollsurg.2007.02.072

23 Gibbs J, Cull W, Henderson W et al. Preoperative serum albumin level as a predictor of operative mortality and morbidity: results from the National VA Surgical Risk Study. Arch Surg 1999; I34:3642. doi:10.100I/archsurg.134.1.36

24 Detsky AS, Abrams HB, McLaughlin JR et al. Predicting cardiac complications in patients undergoing non-cardiac surgery. J Gen Intern Med 1986; I:21 I-19. doi:I0.1007/BF02596I84

25 Cook DJ, Rooke GA. Priorities in perioperative geriatrics. Anesth Analg 2003; 96: I823-36. doi:I0.I2I3/0I.ANE.0000063822.02757.4I

26 Smith TB, Stonell C. Cardiopulmonary exercise testing as a risk assessment method in non-cardiopulmonary surgery: a systematic review. Anaesthesia 2009; 64:883-93. doi:I0.IIIII j. I365-2044.2009.05983.x

27 Eagle KA, Berger PB, Calkins H et al. ACC/AHA Guideline update for perioperative cardiovascular evaluation for noncardiac surgery. J Am Coll Cardiol 2002; 39:542-53. doi:I0.10I6/S07351097(0I)01788-0

28 Fried LP, Tangen CM, Walston J et al. Frailty in older adults: evidence for a phenotype. J Gerontol A Biol Sci Med Sci 200I; 56:146-56.

29 Makary MA, Segev DL, Pronovost PJ et al. Frailty as a predictor of surgical outcomes in older patients. J Am Coll Surg 2010; 210:90I-8. doi:10.1016/j.jamcollsurg.2010.01.028

30 Office for National Statistics. 200 I Census. Available from: http:// www.statistics.gov.uk/hub/health-social-care/index.html

31 Charles Sturt University. Frailty; a robust approach. Wagga Wagga: Charles Sturt University; 2010. Available from: http://www.csu. edu.au/faculty/science/frailty/index.htm 
32 Fleisher LA, Beckman JA, Brown KA et al. ACC/AHA 2007 guidelines on perioperative cardiovascular evaluation and care for noncardiac surgery. Circulation 2007; II6:e4I8-99. doi:I0.I16I/ CIRCULATIONAHA. 107.I85699

33 Poldermans D, Bax JJ, Boersma E. Guidelines for pre-operative cardiac risk assessment and perioperative cardiac management in non-cardiac surgery: the Task Force for Preoperative Cardiac Risk Assessment and Perioperative Cardiac Management in Noncardiac Surgery of the European Society of Cardiology (ESC) and European Society of Anaesthesiology (ESA). Eur Heart J 2009; 30:2769-812.

34 Qaseem A, Snow V, Fitterman $N$ et al. Risk assessment for and the strategies to reduce perioperative pulmonary complications for patients undergoing noncardiothoracic surgery: a guideline from the American College of Physicians. Ann Intern Med 2006; 144:575-80.

35 Hogue CW Jr, Goodnough LT, Monk TG. Perioperative myocardial ischemic episodes are related to hematocrit level in patients undergoing radical prostatectomy. Transfusion 1998; 38:924-31. doi:10.1046/j.1537-2995.1998.38I098440856.x

36 Wu WC, Schifftner TL, Henderson WG et al. Preoperative haematocrit levels and postoperative outcomes in older patients undergoing noncardiac surgery. JAMA 2007; 297:248I-8.

37 García-Erce JA, Cuenca J, Muñoz M et al. Perioperative stimulation of erythropoiesis with intravenous iron and erythropoietin reduces transfusion requirements in patients with hip fracture. A prospective observational study. Vox Sang 2005; 88:235-4. doi:I0.I I I I/j. I423-04I 0.2005.00627.x

38 Marcantonio ER, Goldman L, Mangione CM et al. A clinical prediction rule for delirium after elective noncardiac surgery. JAMA 1994; 27I:134-9.

39 Kalisvaart KJ, Vreeswijk R, de Jonghe JF et al. Risk factors and prediction of postoperative delirium in elderly hip-surgery patients: Implementation and validation of a medical risk factor model. J Am Geriatr Soc 2006; 54:8I7-22. doi:I0.1 I II/j.1532-54I5.2006.00704.x
40 Freter SH, Dunbar MJ, MacLeod H et al. Predicting post-operative delirium in elective orthopaedic patients: the Delirium Elderly At-Risk (DEAR) instrument. Age Ageing 2005; 34:169-84. doi:10.1093/ageing/afh245

4I Lundström M, Olofsson B, Stenvall M et al. Postoperative delirium in old patients with femoral neck fracture: a randomized intervention study. Aging Clin Exp Res 2007; 19:178-86.

42 Stenvall M, Olofsson B, Lundström $M$ et al. A multidisciplinary multifactorial intervention program reduces postoperative falls and injuries after femoral neck fracture. Osteoporos Int 2007; 18:167-75. doi:I0.1007/s00198-006-0226-7

43 Marcantonio ER, Flacker JM, Wright RJ et al. Reducing delirium after hip frature: a randomised trial. J Am Geriatr Soc 200 I; 49:5 I622. doi:I0.1046/j.I532-54I5.200I.49I08.x

44 Duppils GS, Wikblad K. Patients' experiences of being delirious. J Clin Nurs 2007; 16:8I0-8. doi: I0. I I I I/j.I365-2702.2006.01806.x

45 Marcantonio ER, Flacker JM, Michaels $M$ et al. Delirium is independently associated with poor functional recovery after hip fracture. J Am Geriatr Soc 2000; 48:618-24.

46 Edelstein DM, Aharanoff GB, Karp A et al. Effect of postoperative delirium on outcome after hip fracture. Clin Orthop Relat Res 2004; 422:195-200. doi:10.1097/0I.blo.0000128649.59959.0c

47 Harari D, Hopper A, Dhesi J et al. Proactive care of older people undergoing surgery ('POPS'): designing, embedding, evaluating and funding a comprehensive geriatric assessment service for older elective surgical patients. Age Ageing 2007; 36:190-6. doi:I0.1093/ ageing/afl I 63

48 Katz RI, Barnhart JM, Ho G et al. A survey on the intended purposes and perceived utility of preoperative cardiology consultations. Anesth Analg 1998;87:830-6. doi:10.1097/00000539199810000-00016

49 Katz RI, Cimino L, Vitkun SA. Preoperative medical consultations: impact on perioperative management and surgical outcome. Can J Anaesth 2005; 52:697-702. doi:I0.I007/BF030I6556

\section{PATIENT SAFETY AND CLINICAL DECISION MAKING}

\section{Wednesday 19 January 201I}

The aim of this symposium is to explore how the reliability of healthcare can be improved by focusing on the patient-clinician interaction, understanding the clinical decision-making process and how to build safer systems. A live interactive patient simulation session will be included.

Confirmed speakers include:

- Ms Nicola Sturgeon MSP

- Professor Pat Croskerry

- Ms Olivia Giles OBE

Dr Ross Paterson

Dr Rona Patey

Professor Harold Thimbleby

Dr Simon Watson

All grades of medical, nursing, scientific staff and allied healthcare professionals are most welcome, as are those involved in clinical governance, patient safety and quality improvement.
COURSE FEES:

Standard fee: $€ 75$ (inc.VAT) Nurses/AHPs/Pharmacists: $£ 45$ (inc.VAT)

For further details and online booking please visit: http://events.rcpe.ac.uk or contact Margaret Farquhar, 01312473636 or m.farquhar@rcpe.ac.uk 